Onomástica Desde América Latina, n.2, v.1, julho - dezembro, 2020, p.103 - 121. ISSN 2675-2719

https://doi.org/10.48075/odal.v1i2.25489

\title{
Apellidos hispánicos en Centro-Norte de Nueva España, siglo XVI
}

Hispanic surnames in Central-North of New Spain, 16th century

\author{
María Elena Villegas Molina \\ Centro Instituto Nacional de Antropología e Historia Querétaro \\ mevillegas@hotmail.com \\ https://orcid.org/0000-0002-8184-2415
}

Rosa Brambila Paz Instituto Nacional de Antropología e Historia, México Dirección de Etnohistoria de INAH https://orcid.org/0000-0002-6166-0913 rmbrambilap@gmail.com

\section{Resumen}

Los estudios sobre antroponimia permiten examinar la historia de cada población. Para el presente trabajo la indagación se realizó en fuentes documentales del siglo XVI, de donde se obtuvieron apellidos impuestos en una parte de la región Centro - Norte de México. Los individuos de la población primigenia tuvieron su propia antroponimia, antes de la llegada de los conquistadores, sin embargo, fueron objeto de grandes modificaciones por parte de las fuerzas imperiales europeas. En este trabajo se exponen los primeros apellidos hispánicos que se utilizaron para registrar a adultos indígenas como beneficiarios de mercedes. Esta nomenclatura es el origen en México de nominaciones legales en sujetos indígenas.

Palabras clave: siglo XVI; antroponimia; indígenas; Mesoamérica; Jilotepec

\begin{abstract}
:
Studies concerning anthroponymy allow us to examine the history of every population. The investigation for this inquiry was carried out through records from the 16th century. Imposed surnames were obtained from adult indigenous persons in a part of the north central region of Mexico. The individuals of the primordial population had their own anthroponymy, before the arrival of the conquerors, however, they were subject to great modifications by the West European imperial forces. This study presents the first surnames of Spanish origin that were used to register indigenous adults as landowners. This nomenclature is the origin in Mexico of legal nominations in said indigenous subjects.
\end{abstract}

Keywords: Century XVI; anthroponymy; natives; Mesoamérica; Jilotepec 
Onomástica Desde América Latina, n.2, v.1, julho - dezembro, 2020, p.103 - 121. ISSN 2675-2719

https://doi.org/10.48075/odal.v1i2.25489

\section{Introducción}

Cuando Cristóbal Colón llegó al Nuevo Mundo anotó en su diario la presencia de grupos autóctonos e incluso registró una voz indígena, canoa que figura en uno de los primeros diccionarios del español, el Vocabulario de romance en latín de Elio Antonio de Nebrija, escrito probablemente en 1495. El registro de palabras indígenas que designan realidades americanas fue frecuente durante el periodo colonial, incluso se elaboraron diccionarios, gramáticas y vocabularios en varias de las lenguas autóctonas, a las cuales se les da un nombre pues se reconocen como comunidades de habla. Estas obras monumentales, con mucho vocabulario religioso, poco se refieren a los nombres de las personas; en el mejor de los casos dan los nombres de los grupos étnicos. Este hecho no es debido a que los individuos de la población primigenia no hubiesen tenido nombres, sino que sus nombres propios, sus antropónimos, fueron objeto de embates fuertes y directos por parte de las fuerzas imperiales europeas.

Es cierto que muchos cronistas y códices - de origen prehispánico y colonialrelatan la historia antigua mencionando diferentes actores de gestas que con frecuencia tienen el carácter de epopeyas. En los Anales de Cuautitlán, por ejemplo, se narra la historia del joven Ce Acatl que va en busca de su padre. Gracias a estos documentos se pueden reconstruir la sucesión de gobernantes de ciudades como México Tenochtitlán, genealogías o identificar héroes y líderes de momentos críticos en los anales de diferentes localidades. La antroponimia indígena tuvo que ser desplazada cuando los europeos iniciaron el proceso de colonización. La ocupación de territorios invadidos se lograba inmediatamente por la fuerza, pero la consolidación de la conquista dependía de la capacidad de asimilación de los pueblos sometidos, y estaba supeditada a la labor más sutil y penetrante, primero de la 
Onomástica Desde América Latina, n.2, v.1, julho - dezembro, 2020, p.103 - 121. ISSN 2675-2719

https://doi.org/10.48075/odal.v1i2.25489

evangelización y después de las políticas educativas y culturales de la corona española. En

ese proceso y condiciones la población autóctona se vio precisada a tener una nueva identidad individual pues la suya se transformó con la implantación de los nuevos vínculos entre los grupos humanos.

En la antigua Mesoamérica o América Meridional, investigadores de regiones de Oaxaca, Chiapas, Guatemala, Yucatán, Michoacán y el valle de México han llevado a cabo estudios sobre las continuidades y rupturas con respecto a los nombres propios en diferentes comunidades. Sus indagaciones se basan, fundamentalmente, en documentos como los registros de bautizo, los testamentos e incluso en documentación elaborada en la lengua de los pueblos originarios. ${ }^{1}$ Poca atención han recibido los grupos que se encontraban en los márgenes de las altas civilizaciones, como el otomí. Este grupo es reconocido como uno de los más antiguos de la geografía del altiplano central mexicano, con una población muy numerosa. El cronista Torquemada al referirse a los otomíes, dice que “[...] casi comienza allí la grandísima provincia o reino de los otomíes, que coge a Tepexi, Tula, Xilotepec, cabeza de este reino, Chiapa, Jiquipilco, Actopan y Querétaro, en cuyo medio de esos pueblos referidos hay otros innumerables porque lo eran sus gentes, y distintas de los mexicanos" (TORQUEMADA, 1986, v. 1: 393). Dorantes de Carranza asienta que "los que son verdaderos moradores y naturales, son los otomítes, gente vascongada y montañesa” (DORANTES DE CARRANZA, 1902 [1604]: 3-4). De igual modo, en las mismas fuentes nahuas se les adjudica el papel de guerreros, gente valerosa y

\footnotetext{
${ }^{1}$ Recuentos sobre las investigaciones de las formas en que las poblaciones autóctonas nombraban a los individuos en la época del dominio español se encuentran, entre otros, en Lockhart, 1999, especialmente en el rubro "Evolución de los patrones de nombres propios" pp. 173-191; y recientemente en el de Kirkhusmo, 2012.
} 
Onomástica Desde América Latina, n.2, v.1, julho - dezembro, 2020, p.103 - 121. ISSN 2675-2719

https://doi.org/10.48075/odal.v1i2.25489

calurosos en la lujuria. (ESCALANTE, 1998: 164-165) ${ }^{2}$ La forma en que este grupo primigenio transformó y adaptó los nombres de los individuos es el tema de este trabajo.

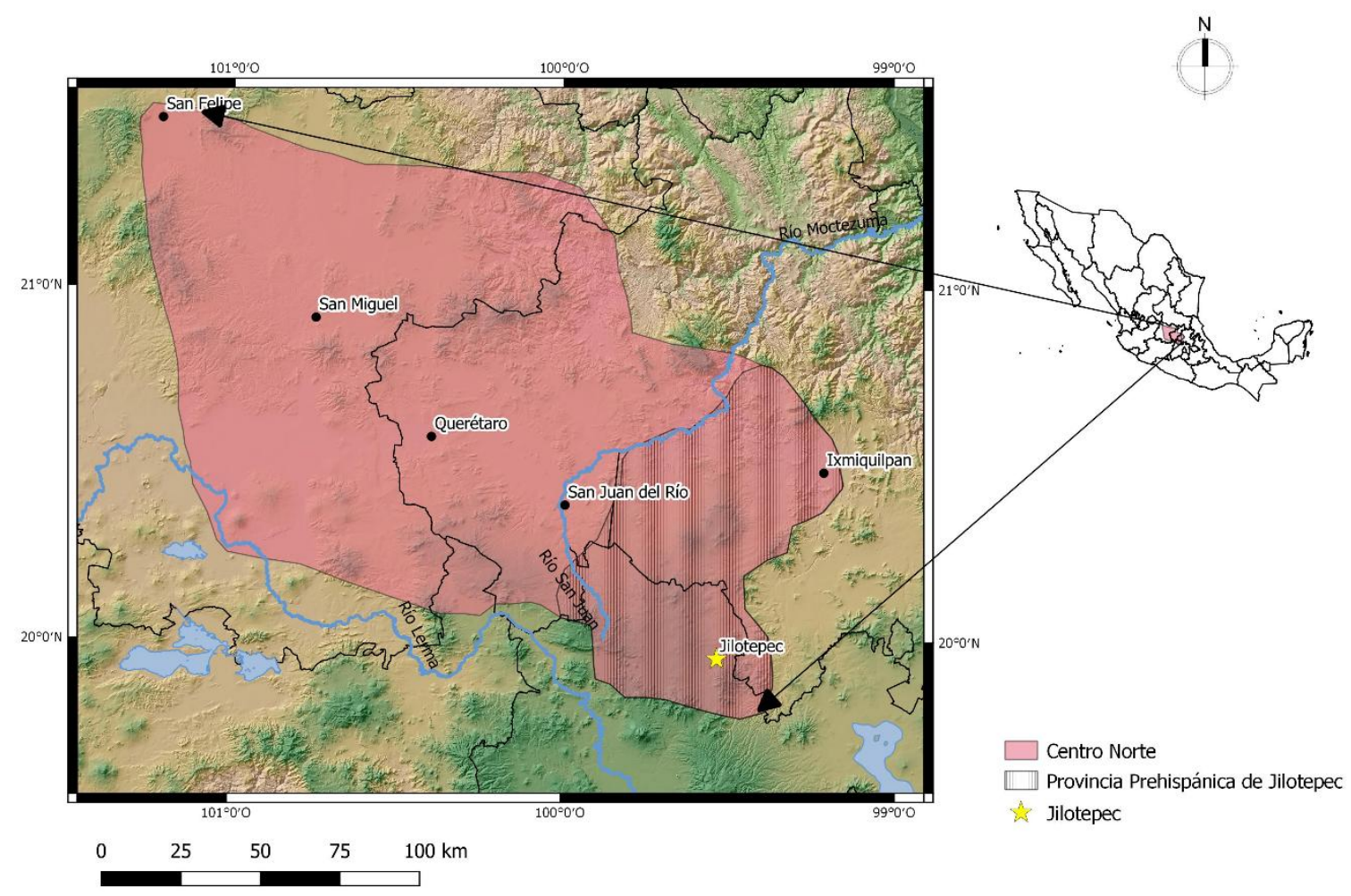

Figura 1. El territorio otomí en el siglo XVI (Elaborado por Alejandro García Kobeh).

La información que se expone en este trabajo proviene de la revisión de expedientes del grupo documental Mercedes del Archivo General de la Nación de México, correspondientes a la jurisdicción de la alcaldía mayor de Jilotepec, en el siglo XVI. Los primeros volúmenes de este acervo en realidad son los libros donde se registraron las primeras medidas de gobierno generadas durante las décadas iniciales de la administración

\footnotetext{
${ }^{2}$ Una visión más completa sobre el todo social de los otomíes se encuentra en Carrasco, 1987.
} 
Onomástica Desde América Latina, n.2, v.1, julho - dezembro, 2020, p.103 - 121. ISSN 2675-2719

https://doi.org/10.48075/odal.v1i2.25489

virreinal. En ellos se encuentra gran variedad de información con respecto a las acciones despachadas por las autoridades, tanto de la Audiencia como de los virreyes. ${ }^{3}$

Los documentos revisados usualmente registran el nombre del sujeto legal. En ocasiones se plasman algunas características de los individuos como son: lugar de residencia, el grupo social de pertenencia, estado civil, entre otros. En el caso de la población autóctona también se hacía referencia a su población de origen, el cargo que tenía y dónde lo ejercía, se señala, asimismo, un título jerárquico, si lo tenía, lo que permite reconocer el origen étnico de los individuos, de modo que el antropónimo y sus acotaciones fueron elementos importantes en el estudio de la distinción de quienes pertenecían a uno u otro sector de la población. Lo más evidente es cuando en el texto se especifica que es ‘indio' o 'natural', o cuando llevan el reconocimiento de 'cacique' y 'principal', títulos de uso exclusivo para la población autóctona; ${ }^{4}$ algunos de ellos llevaban el tratamiento de ‘don'. Otro modo de distingo para los mesoamericanos fue que el individuo recibía determinados tipos de prebenda como el uso de montura, de espadas, la posibilidad de criar ganado y, por supuesto, el recibir tierras en nombre de su comunidad o a título personal.

Dado que se trata de libros en los que se asentaron los primeros actos de gobierno español en la Nueva España, proponemos que los nombres personales que se registran en estos documentos tienen una doble faceta: por un lado, es factible que, por tratarse de testimonios oficiales, en la práctica cotidiana se haya optado, coercitivamente, por rechazar la continuidad y persistencia de la historia antroponímica nativa. En efecto, en condiciones

\footnotetext{
${ }^{3}$ Del Paso y Troncoso, 1905; O’Gorman, 1939; Zavala, 1982 y Gerhard, 1992, han resaltado la presencia de documentación concerniente al gobierno virreinal y enfatizan su importancia para los estudios de aspectos económico, político, social y religioso de la primera mitad del siglo XVI.

${ }^{4}$ Desde 1538, la Corona prohíbe expresamente dar el título de señor a la nobleza indígena dentro de las diferentes comunidades. A los que tenían un reconocimiento social se les nombraría principales y caciques, así se expresa en el libro VI, Título VII "De los caciques" y la Ley V del mismo libro que se intitula "Que los indios caciques y principales no se intitulen señores", mandamiento del emperador don Carlos y la Emperatriz hecho en Valladolid el 26 de febrero de 1538 (Paredes, 1681).
} 
Onomástica Desde América Latina, n.2, v.1, julho - dezembro, 2020, p.103 - 121. ISSN 2675-2719

https://doi.org/10.48075/odal.v1i2.25489

donde prevalece la situación de colonizador/colonizado, lo que interesa al invasor es que prevalezcan las relaciones jerarquizadas. Por otro lado, es muy probable que la población nativa utilizara esos nuevos nombres como estrategia para defender su derecho ancestral a la tierra y recomponer sus antiguas formas de relaciones sociales para sobrevivir ante la nueva realidad. Se admite la contradicción propia de la sociedad sometida que adquiere elementos de sus sojuzgadores, pero el contenido y finalidades van acordes a sus intereses. La anotación por escrito de los nombres individuales, amén de su valor jurídico, adquiere otro significado en una comunidad que resguarda sus costumbres ancestrales de forma oral. Por la vía escrita se fincan las relaciones con el dominador, pues el nombre propio escrito en la merced por la autoridad daba legalidad a la tenencia de la tierra.

En las siguientes líneas, primero se esboza la forma en que se daba nombre a los individuos en la época prehispánica y luego se desglosa la información recabada sobre los nombres utilizados por las poblaciones otomíes del Centro-Norte.

\section{La tradición mesoamericana de poner nombres}

La cultura mesoamericana a partir de los signos del tonalpohualli no sólo designaba a las personas específicas sino también se nombraba a los dioses, al tiempo y al espacio. Ese calendario ritual de 260 días constaba de 20 nombres que se engranaban con un ciclo rotativo de 13 numerales. Fray Bernardino de Sahagún en el libro VI de su obra describe la ceremonia realizada por los nahuas para dar nombre a un recién nacido (SAHAGÚN, 1977, t. I: 361 y t. II : 204 y ss.). La práctica onomástica de dar nombre a partir del día de nacimiento no era muy ortodoxa. Si el día era propicio se conservaba el nombre calendárico, pero cuando no lo era, diferían la celebración a otro día. Importante fue 
Onomástica Desde América Latina, n.2, v.1, julho - dezembro, 2020, p.103 - 121. ISSN 2675-2719

https://doi.org/10.48075/odal.v1i2.25489

seleccionar el signo para conocer la ventura que había de tener el individuo. El fraile

cronista aclara que

Acabadas todas estas ceremonias ponen nombre al niño de alguno de sus antepasados, para que levante la fortuna y suerte de aquel cuyo nombre le dan: este nombre le pone la partera o sacerdotisa [...]. Pongo por caso que le pone por nombre Yáotl; comienza a dar voces, y habla como varón con el niño y dícele de esta manera: 'Yáotl -que quiere decir hombre valiente- recibe, toma tu rodela, toma el dardo, que estas son tus recreaciones y regocijos del sol'. Y luego le ponía la mantilla atada sobre el hombro y le ciñe un maxtli.( SAHAGÚN, 1977, t. II :208)

También era frecuente que por su desempeño en la vida los individuos recibieran otro nombre, a manera de apodo, el cual, con frecuencia, tenía más vigencia que el calendárico. Igualmente, en el nombre podía estar el rango, un ejemplo: Ce Ácatl Topiltzin Quetzalcóatl: Ce Acatl, es la fecha 'uno caña' del calendario ritual, Topiltzin es porque era miembro de la clase dirigente formado de la apócope reverencial -tzin, y Quetzalcóatl es el nombre de uno de los dioses, Uno Caña nuestro venerable señor. Esta práctica onomástica de dar nombres personales a partir del signo del día del calendario de 260 días está relacionada con los conceptos mesoamericanos de destino. Más de la mitad de los signos calendáricos son nombres de animales, otros de elementos vegetales e incluso de elementos arquitectónicos como 'casa'. Así, los individuos pueden llevar nombres de animales, plantas, etcétera.

Esta información, de gruesos trazos, no es suficiente ni rinde cuenta del complejo régimen de antropónimos que había en Mesoamérica. Se sabe que, en ciertos tiempos y lugares, las personas de alto rango solían tener nombres ocultos, sucesivos o alternativos. También hubo nombres que refieren proezas de guerra, características físicas o emocionales y algunos otros, metáforas líricas. Es importante tener claro que, por ejemplo, en el centro de México "de conformidad con los principios de parentesco nahuas, nada en los nombres 
Onomástica Desde América Latina, n.2, v.1, julho - dezembro, 2020, p.103 - 121. ISSN 2675-2719

https://doi.org/10.48075/odal.v1i2.25489

indicaba 'familia', aunque en ciertas dinastías reales se usaban los mismos nombres en generaciones sucesivas, asociando así un conjunto de nombres con una dinastía y con gobernaciones específicas. Aparte de eso, hasta donde se sabe, al menos los nombres masculinos no variaban mucho con el rango social" (LOCKHART, 1999: 174). Lo que se puede afirmar es que la tradición antroponímica provee de identidad tanto a los hombres, a las divinidades y a los fenómenos espaciotemporales. Así, los nombres mesoamericanos fueron capaces de hacer numerosas distinciones y, potencialmente, cubrir el género, la edad, la descendencia, el rango, la filiación étnica o regional, entre otros aspectos (LOCKHART, 1999: 173). 
Onomástica Desde América Latina, n.2, v.1, julho - dezembro, 2020, p.103 - 121. ISSN 2675-2719

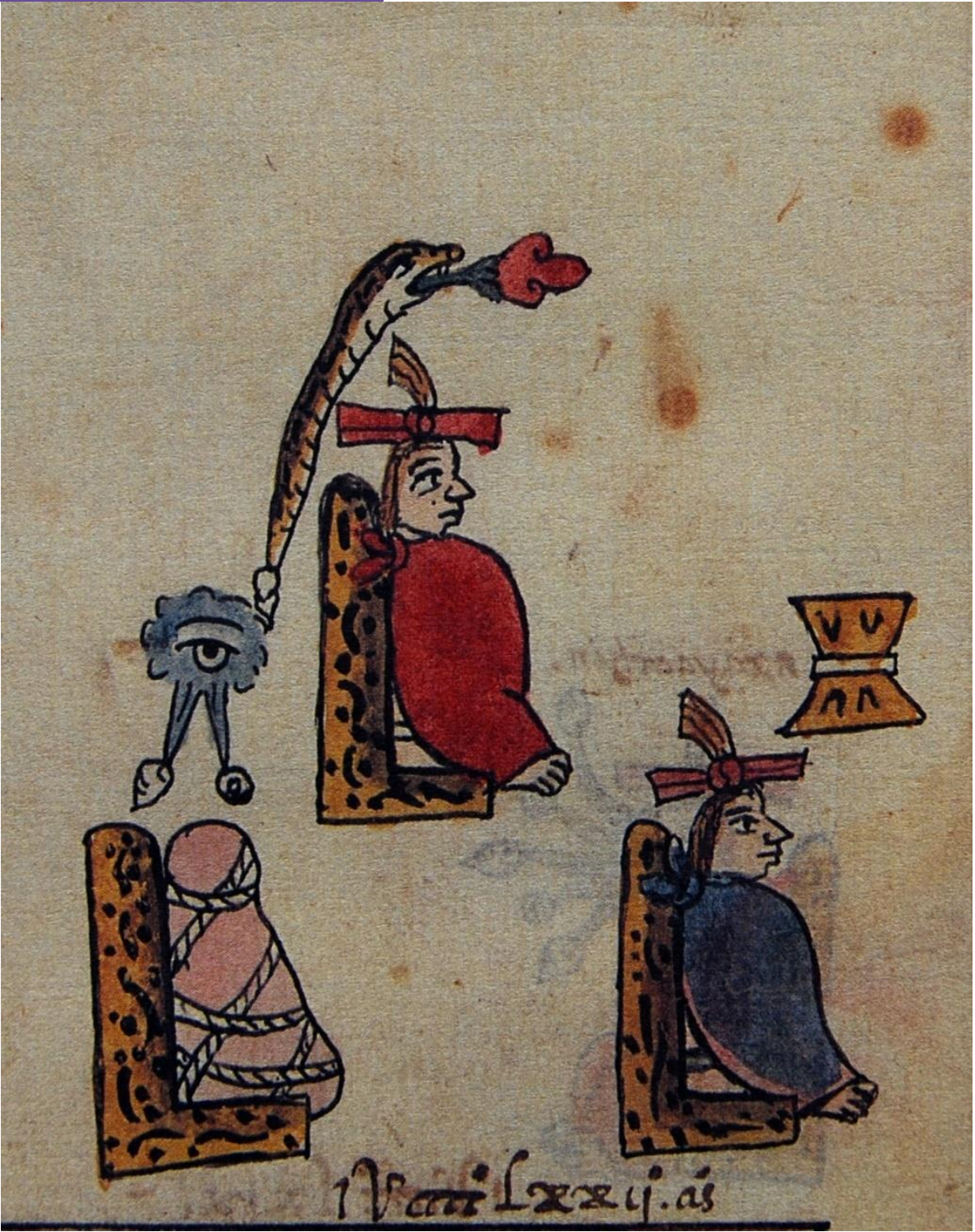

Figura 2. Detalle de la lámina 46 del Códice de Huichapan (Fotografía Proyecto de la Provincia tributaria de Jilotepec).

Las pictográficas de factura mesoamericana, son una fuente más para conocer el

régimen onomástico de los grupos mesoamericanos. Hay que traer a la memoria que la escritura en el México antiguo, a diferencia de la europea, no era alfabética sino que se basó en signos gráficos. El estudio de los códices ha sido un camino largo y muy fructífero. No todos los glifos antroponímicos de estos documentos representan el nombre calendárico, con frecuencia los personajes tienen otro tipo de apelación. Las convenciones para representar los glifos onomásticos han sido detectadas por varios especialistas quienes 
Onomástica Desde América Latina, n.2, v.1, julho - dezembro, 2020, p.103 - 121. ISSN 2675-2719

https://doi.org/10.48075/odal.v1i2.25489

establecen varias categorías. Por ejemplo, en el Códice de Tepeticpac los nombres de algunos personajes tienen su glifo onomástico de la manera acostumbrada, es decir representado por encima o a un lado del personaje, pero, además, tienen otro nombre, al cual Aguilera le llama epíteto (Aguilera, (1998: 30). Para su lectura divide los glifos onomásticos en diferentes grupos: antropomorfos (representación del cuerpo humano o de alguna de sus partes), zoomorfos, fitomorfos, objetos de la naturaleza y un grupo de símbolos o de cultura (aquéllos que recuerdan productos elaborados por el hombre); entre estos últimos distingue: construcciones, armas, banderas, fiestas, etcétera. En la figura 2 se muestran ejemplos de estas denominaciones gráficas en uno de los códices elaborados en la región otomí, objeto de este estudio. ${ }^{5}$

La clasificación de los glifos antroponímicos que han hecho los especialistas en códices hace eco en documentos alfabéticos. Lockhart en escritos nahuas encuentra nombres de individuos que agrupa también por lo que representarían: metáforas poéticas: Diego Xochtonal $=$ Destino de Flor; marciales y religiosos: Juan Yaomitl $=$ Flecha de Guerra; animales, signos calendáricos: Melchor Quauhtli = Águila; apodo sardónico Jerónimo Tlaxcalcecec $=$ Tortilla Fría; títulos: Juan Colhuateuctli $=$ Señor de la Gente de Culhuacan; por su pertenencia a un altépetl o calpulli: Francisco Huitziltecalt $=$ habitante de Huitzillan (LOCKHART, 1999: 189).

A la llegada de los españoles, el bautismo fue el inicio del proceso de cambio en la antroponimia indígena. Cada recién bautizado recibía un nombre cristiano, que posiblemente escogía quien realizaba la ceremonia, con frecuencia multitudinaria. Al igual que muchos judíos conversos en España, en México se tomaron nombres comúnmente de

${ }^{5}$ El Códice de Huichapan ha sido objeto de varios estudios, Alvarado, 1976; Caso, 1930; y el de Ecker publicado por Lastra y Bartholomew, 2001. Existe una edición facsimilar del documento hecha por Reyes, 1992. 
Onomástica Desde América Latina, n.2, v.1, julho - dezembro, 2020, p.103 - 121. ISSN 2675-2719

https://doi.org/10.48075/odal.v1i2.25489

un santo o bien de algún religioso, como fue el caso de fray Juan de Granada, comisario general de los franciscanos, quienes llegaron en épocas muy tempranas a Jilotepec. Pero veamos de cerca el proceso en la región otomí del Centro-Norte. Es importante remarcar que los nombres propios de los indígenas plasmados en la información documental aquí trabajada son de adultos que luchan por tener una presencia jurídica dentro de un aparato legal ajeno a su cultura.

\section{Los apellidos de origen hispánico en población indígena}

La validez de estos primeros nombres en volúmenes de la administración virreinal hubo de tener un fuerte asentamiento para dar lugar a un nuevo concepto de la nomenclatura indígena, que se perpetuaría a través de los siglos, como el formato admitido para la identidad del individuo mexicano. Con la imposición de nombres cristianos, el reemplazo de la antroponimia mesoamericana fue inminente.

Los documentos de Jilotepec contienen un gran número de nombres propios, con los que se conformó el corpus base del presente estudio, en él se registran nombres de personajes españoles e indígenas. Para este estudio, como se indicó antes, se expondrán únicamente los nombres españoles que fueron asignados a adultos de origen indígena para el otorgamiento de mercedes, enfocándonos en el segundo nombre o apellido, con el propósito de identificar cuáles de ellos tuvieron un mayor auge al inicio de la conquista y su integración. Este dato es útil en el conocimiento histórico de la derivación nominal en la etnia otomí de la región Centro-Norte de México.

Cada una de las mercedes aparece fechada, dato que permitió acopiar el acervo nominal por décadas. Los datos obtenidos se revisaron desde 1530 hasta 1614 , y su 
Onomástica Desde América Latina, n.2, v.1, julho - dezembro, 2020, p.103 - 121. ISSN 2675-2719

https://doi.org/10.48075/odal.v1i2.25489

clasificación de cada diez años permite observar la proclividad y orden de aparición de los apellidos hispánicos.

Dado que se trata de libros en los que se asentaron los primeros actos de gobierno español en la Nueva España, es factible que, por tratarse de testimonios oficiales, en la práctica cotidiana se haya optado, coercitivamente, por no aceptar la continuidad y persistencia de la historia antroponímica nativa. Los sacerdotes que llegaron a cristianizar percibieron rápidamente la religiosidad indígena, por lo que el bautizo prontamente fue uno de sus aliados.

\section{Década 1530}

En esta década únicamente se presentan dos registros en el año de 1537: Juan Bautista del Castillo y Manuel de Santiago, ambos del 27 de noviembre. En estudios diversos, como el de Bowman (1970), el nombre de Juan es de los más atribuidos en la Nueva España desde la llegada de los conquistadores.

\section{Década 1540}

Aparece en los años de 1543 y 1544 el registro de trece individuos indígenas a quienes se les asigna un solo nombre hispánico, es decir, constan de una pieza léxica. Así entonces, se introducen en el concepto nominal mesoamericano diez vocablos que aparecen en el orden que se anotan en seguida, y su repetición es el número que está entre paréntesis:

Gabriel (1), Miguel (1), Pablo (1), Francisco (2), Diego (2), Martín (1), Agustín (1), Alonso (1), Antón (2), Juan (1).

Como se puede observar, los nombres de Diego, Francisco y Antón se repiten en estos años, en personas que provienen de espacios geográficos distintos. El bajo número de individuos registrados en esta década, así como los nombres de una sola pieza léxica en los inicios documentales, pudiera ser factor para la no necesaria presencia de un segundo 
Onomástica Desde América Latina, n.2, v.1, julho - dezembro, 2020, p.103 - 121. ISSN 2675-2719

https://doi.org/10.48075/odal.v1i2.25489

nombre para establecer su identidad, tomando en consideración que se estaba iniciando el proceso de legalización de mercedes.

\section{Década 1550}

En esta siguiente década ya aparecen algunos apellidos. El registro es de (31) individuos indígenas, de los cuales (27) llevan nombre de dos piezas léxicas. El recurso del apellido advierte la precisión de incrementar el repertorio nominal para los indígenas inscritos en los documentos de mercedes. Los cuatro que constan de una pieza léxica son: Alonso, Andrés, Domingo y Hernando.

El uso de patronímicos hispánicos en la región que nos ocupa evidentemente no cumple con su función de antecedente familiar, ya que el único fin en ese momento era nombrar y apellidar a adultos que requerían tener un registro oficial para la posesión de su merced con nombre hispánico, sin importar que no fueran 'hijos de'. Lo mismo ocurre con los toponímicos, que desde sus orígenes reiteradamente han sido adoptados por ancestros por causas diversas sin corresponder precisamente al lugar del que proceden.

Enseguida se expone el listado correspondiente a los (24) vocablos que en esta década de 1550 se integran a la nominación mesoamericana como apellidos. Este es su orden de aparición cronológica y número de ocurrencias:

Sánchez (2), López (1), De Luna (3), De la Montaña (1), Ramírez (1), Freyle (1), De Guzmán (1), De la Cruz (1), De San Juan (1), García (1), Flores (1) Rivas (1), De Castilla (1), De Granada (1), De San Mateo (1), De San Miguel (1), Culsa (1), Gómez (1), Nájera (1), Nicolás (1), Velázquez (1), Vizcaino (1), De San Luis (1), De Tapia (1).

Como se observa, el primer apellido que se impone a los indígenas es Sánchez. Las dos ocasiones en que este patronímico aparece son junto al nombre de Pedro, uno en 1550 y otro en 1555. El primero es indio principal y natural de Tepexi, el segundo es natural de 
Onomástica Desde América Latina, n.2, v.1, julho - dezembro, 2020, p.103 - 121. ISSN 2675-2719

https://doi.org/10.48075/odal.v1i2.25489

Jilotepec. También en esta década aparecen los primeros apellidos hagiónimos, los tres con la preposición ‘de’ antepuesta: San Juan, San Mateo y San Miguel.

\section{Década 1560}

En esta década el número de individuos indígenas registrados con nombres hispánicos en los documentos de mercedes, suman (20), de los cuales (19) tienen apellido, con una amplia variedad léxica de (15) vocablos. La reiteración cayó en De la Mota en (3) ocasiones, Jiménez y León en (2) cada uno. En este grupo, la doctrina quedó ausente pues no se registraron hagiónimos como apellidos, los de orden toponímico tuvieron mayor presencia. En este grupo aparece en segunda posición el nombre de pila Damián, que bien puede ser un segundo nombre o apellido. El número de veces que se manifiestan es como sigue y se anotan en el orden cronológico en que aparecen:

Maldonado (1), De la Mota (3), De Villegas (1), Damián, (1), De Ledezma (1), Luna (1), Moreno (1), De Sotomayor (1), García (1), Jiménez (2), De la Montaña (1), De León (2), Pinelo (1), Aquino (1), Grande (1).

\section{Décadas 1570 y 1580}

Estas dos décadas se trabajaron en conjunto por los pocos datos antroponímicos registrados en las mercedes. En la de 1570 se encontró sólo (1) nombre, Juan de Ávalos, y, en la de 1580 (4): Diego García, Mateo Morales, Pedro de Mendoza, y (1) nombre sin apellido: Gabriel.

\section{Década 1590}

En esta década se incrementa considerablemente el número de individuos indígenas registrados en los documentos. A excepción de un nombre, todos los demás (66) constan de dos piezas léxicas. Con el incremento de registros aumentó el número de vocablos que se integraron en la nominación del indígena otomí, que resultó en (34) apellidos, de los cuales 
Onomástica Desde América Latina, n.2, v.1, julho - dezembro, 2020, p.103 - 121. ISSN 2675-2719

https://doi.org/10.48075/odal.v1i2.25489

(4) nombres de pila aparecen en segundo lugar. Como señalamos antes, bien pudo tratarse de nombres compuestos, aunque en estos documentos no han sido numerosos esos casos. Dichos nombres son:

Martín (2), Damián (1), Zacarías (1) y Vicente (1).

A lo largo de los documentos de mercedes, el nombre Vicente se observa como nombre de pila en dos ocasiones, y como apellido una; Zacarías sólo aparece una ocasión como apellido y nunca como nombre; Damián aparece sólo como apellido en dos ocasiones; en cuanto a Martín, se registra una ocasión como nombre y dos como apellido. En la indagación de Zabalza (2018: 109-148) sobre la antroponimia de Navarra, ella especifica que los nombres de pila, al ser usados como apellidos, serán transmitidos a generaciones posteriores, pero ello no significa que todos los nombres de pila sean susceptibles a usarse como apellidos, pues se trata de un registro culto, que les concierne a nombres de reyes como Carlos, Felipe, Alfonso, Jaime y Luis. Es de hacer notar que ninguno de estos nombres de registro culto aparece como apellido en personajes indígenas de la región otomí, y tampoco surgen como nombre de pila.

En esta misma década el apellido García se presenta en dos homonimias, uno corresponde a dos mujeres que llevan por nombre Isabel García, la primera registrada en junio de 1591, viuda, india de Jilotepec, la otra en agosto de 1593, india de la estancia de San Jerónimo. El otro caso corresponde a dos hombres llamados Rafael García, uno registrado en mayo de 1593, indio cacique de Jilotepec y el otro cacique del pueblo de San Andrés Timilpa, de septiembre de 1593. La frecuencia de los nombres registrados en esta década es como sigue, y se presentan en el orden cronológico en que aparecen en los documentos: 
Onomástica Desde América Latina, n.2, v.1, julho - dezembro, 2020, p.103 - 121. ISSN 2675-2719

https://doi.org/10.48075/odal.v1i2.25489

García (13), De Granada (6), Hernández (1), De los Ángeles (7), Ávalos (2), Martín (2), Alvarado (1), San Francisco (1), De la Bárcena (1), González (5), De Guzmán (1), Jiménez (1), Damián (1), De Luna (1), De la Barsana (1), Deguinga (1), De Aquino (1), Galván (1), Macías (1), Rivas (1), Zacarías (1), Juárez (1), Ruiz (1), San Antonio (1), De la Mota (4), De la Vera (1), De los Morales (1), Sánchez (1), Vicente (1), De Santiago (1), De Vega (1), López (1), Pérez (2), De Castilla (1).

De este conteo se desprende que el mayor número de repeticiones correspondió a García con (13) ocurrencias, le sigue De los Ángeles con (7), De Granada con (6), González con (5), De la Mota con (4). Ávalos, Martín y Pérez tuvieron (2) reiteraciones cada uno, los demás apellidos contaron con solo (1) registro.

\section{Década de 1600}

En esta década el registro es de (10) personas indígenas con nombres cristianos, de los cuales dos son de sólo una pieza léxica: Bonifacio y Magdalena. Los demás nombres constan de nombre y apellido, su número de ocurrencias y orden de aparición es como sigue:

Damián (1), García (1), De Vega (1), Ávalos (1), De la Mota (1), Pérez (1), De Luna (1), De la Bárcena (1).

\section{Consideraciones finales:}

El inicio de la antroponimia en la Nueva España trajo consigo apellidos patronímicos como García, Sánchez, López, Jiménez, Ramírez, Gómez, Velázquez, Hernández, González, Ruiz y Pérez. La función del sufijo -ez en el patronímico hispánico marca la descendencia o la filiación: 'hijo de', condición que, en los casos aquí expuestos, difiere al ser asignados a adultos sin parentesco de origen, que, sin embargo, dieron cabida a nuevas convenciones nominales a partir del siglo XVI. Aun así, estos apellidos pasaron a formar parte de los nombres de familia en México. 
Onomástica Desde América Latina, n.2, v.1, julho - dezembro, 2020, p.103 - 121. ISSN 2675-2719

https://doi.org/10.48075/odal.v1i2.25489

La aportación léxica en los documentos revisados fue cuantiosa, preferentemente en apellidos de orden toponímico, mientras que los derivados de la hagionimia fueron realmente pocos, siete: Santiago, San Juan, San Mateo, San Miguel, San Luis, San Francisco y San Antonio. Los de menor número fueron los nombres de pila con función de apellido, sólo cinco: Nicolás, Damián, Martín, Zacarías y Vicente. De esta información se puede considerar que para el conteo de individuos indígenas que debieron quedar registrados en las mercedes, se haya recurrido a la repetición de nombres pertenecientes a los propios españoles que llegaron.

El análisis de los apellidos del siglo XVI en el Centro-Norte de la Nueva España permite conocer aspectos del proceso de colonización y dominio poco señalados hasta el momento. Haber recurrido inicialmente al cambio de nombre de personas indígenas y después a adjudicarles un apellido, trasciende en un punto germinal de colonización, pues la antroponimia fungió como mediador en la introducción de la doctrina que sustentaría una nueva nomenclatura, la cual a corto plazo resultó de gran utilidad en la integración de los que iban llegando, con la cotidianidad nominal.

La transformación que sufre el dar nombre en dicha región durante un siglo tan revolucionario como el XVI, está inmerso en los cambios del todo social y el surgimiento de nuevas instituciones. El proceso de renombrar y su potencial de reconstruir la realidad en la que estuvieron inmersos los grupos otomíes del Centro-Norte, hace de la onomástica una herramienta heurística invaluable.

La necesidad de designar a cada persona con un vocablo determinado en la situación de colonización del siglo XVI en la Nueva España adquiere características especiales en la historia de la antroponimia. El nombre nace como una necesidad del lenguaje, por ello al 
Onomástica Desde América Latina, n.2, v.1, julho - dezembro, 2020, p.103 - 121. ISSN 2675-2719

https://doi.org/10.48075/odal.v1i2.25489

enfrentarse dos comunidades con formas distintas de individualizar a los sujetos, se entra en conflicto. En la tradición europea, el verdadero nombre era el del bautismo cristiano pues se reconocía al individuo una independencia personal, mientras que en Mesoamérica la comunidad era el verdadero cuerpo social que daba a sus miembros identidad.

La importancia de la escritura de los nombres en los documentos trabajados no solamente se trata de la nueva antroponimia con que los conquistadores denominan en los textos legales a los individuos que van incorporando, sino que muestran que se quiere borrar de un plumazo la forma colectiva de tenencia de la tierra e implementar una forma inédita para los grupos mesoamericanos, la propiedad individual.

Una última observación es que el nuevo repertorio de nombres cristianos en uso en la época era mucho menos variado que el prehispánico.

Recebido em30/04/2020

Aceito em 30/06/2020

Publicado em 29/07/2020

\section{Referencias}

Aguilera, Carmen. (1998). Lienzos de Tepeticpac. Estudio iconográfico e histórico, Gobierno del Estado de Tlaxcala, México.

Alvarado Guinchard, Manuel. (1976). El códice de Huichapan. I. Relato otomí del México prehispánico y colonial, Departamento de Lingüística, Instituto Nacional de Antropología e Historia, México.

Boyd Bowman, Peter. (1970). "Los nombres de pila en México desde 1540 hasta 1950”, Nueva Revista de Filología Hispánica (NRFH), 19 (1), pp. 12-48.

Carrasco, Pedro. (1987). Los otomíes. Cultura e historia prehispánica de los pueblos mesoamericanos de habla otomiana, Biblioteca Enciclopédica del Estado de México, Gobierno del Estado de México, México. 
Onomástica Desde América Latina, n.2, v.1, julho - dezembro, 2020, p.103 - 121. ISSN 2675-2719

https://doi.org/10.48075/odal.v1i2.25489

Caso, Alfonso. (1930). "Un códice en otomí”, XXIII Congreso Internacional de Americanistas, pp. 130-135, Sociedad de Americanistas, Nueva York.

Dorantes de Carranza, Baltazar. (1902) [1604] Sumaria relación de las cosas de la Nueva España, con noticia individual de los descendientes legítimos de los conquistadores y primeros pobladores españoles, la publica por primera vez el Museo Nacional de México paleografiada por el Sr. D. José María de Agreda y Sánchez, Imprenta del Museo Nacional, México.

Escalante Gonzalbo, Pablo. (1998). “Los otomíes en el México prehispánico”, Historia general del Estado de México, 2, Época Prehispánica y siglo XVI, pp. 161-185, Gobierno del Estado de México, El Colegio Mexiquense, México.

Gerhard, Peter. (1992). Síntesis e índice de los mandamientos virreinales 1548-1553, UNAM, México.

Kirkhusmo Phara, Lars. (2012). “"Tonalism': name, soul, destiny and identity determined by the 260-day calendar in Mesomerica", Botolv Helleland, Christian-Emil Ore y Solvelg Wikstrem, eds. Names and Identities. Oslo Studies in Language, v. 4, núm. 2, pp. 184- 203, Universidad de Oslo, Oslo

Lastra, Yolanda y Doris Bartholomew (eds.). (2001). Códice de Huichapan. Paleogrfía y traducción de Lawrence Ecker, Instituto de Investigaciones Antropológicas, Universidad Naccional Autónoma de México, México.

Lockhart, James. (1999). Los nahuas después de la Conquista. Historia social y cultural de la población indígena del México central, siglos XVI-XVIII, Fondo de Cultura Económica, México. 
Onomástica Desde América Latina, n.2, v.1, julho - dezembro, 2020, p.103 - 121. ISSN 2675-2719

https://doi.org/10.48075/odal.v1i2.25489

O’Gorman, Edmundo. (1939). "Mandamientos del Virrey don Antonio de Mendoza", Boletín, tomo X, pp. 213- 311, Archivo General de la Nación, México.

Paredes, Julián. (1681). Recopilación de las leyes de los reinos de Indias, mandadas imprimir y publicar por la Majestad Católica del Rey don Carlos II, nuestro señor, va dividida en cuatro tomos, Madrid.

Paso y Troncoso, Francisco del. (1905). Papeles de Nueva España publicados de orden y con fondos del gobierno mexicano, 2a . Serie, Geografía y Estadística, México.

Reyes Retana, Óscar. (1992). Códice de Huichapan, Telecomunicaciones, México.

Sahagún, Fray Bernardino de. 1977. Historia general de las cosas de Nueva España, edición de Ángel María Garibay, Porrúa, México.

Torquemada, fray Juan de. (1986). Monarquía Indiana. De los veinte y un libros rituales y monarquía indiana, con el origen y guerra de los indios occidentales y de sus poblazones, descubrimiento, conquista conversión y otras cosas maravillosas de la misma tierra, edición preparada por Miguel León-Portilla, 7 vols., Instituto de Investigaciones Históricas, Universidad Nacional Autónoma de México, México.

Zavala, Silvio. (1982). Libros de Asientos de la Gobernación de la Nueva España. Período del Virrey don Luis de Velasco, 1550-1552, Archivo General de la Nación, México.

Zabalza Seguín, Ana. (2018). "Por no pertenecerles el apellido. La formación de los apellidos en la Navarra Moderna". Publicado en De Engracia a Garazi, el misterio de los nombres en Navarra. Ana Zabalza S. Directora. Universidad de Navarra, España. 